\title{
Height Detection and Analysis of Water Flowing Fractured Zone of Coal Face
}

\author{
Ziyang Feng \\ College of Resources, Shandong University of Science and Technology, Tai'an, China \\ Email:mh2623@126.com
}

How to cite this paper: Feng, Z.Y. (2021) Height Detection and Analysis of Water Flowing Fractured Zone of Coal Face. Computational Water, Energy, and Environmental Engineering, 10, 131-139. https://doi.org/10.4236/cweee.2021.104010

Received: July 28, 2021

Accepted: August 20, 2021

Published: August 23, 2021

Copyright $\odot 2021$ by author(s) and Scientific Research Publishing Inc. This work is licensed under the Creative Commons Attribution International License (CC BY 4.0).

http://creativecommons.org/licenses/by/4.0/

(c) (i) Open Access

\begin{abstract}
Taking 91105 working face as the research object, the observation method of water flowing fractured zone and the layout of mining holes were determined by analyzing the field geological structure. It was shown that the fractured zone height and the ratio given by the measured method were 52.33 and 12.46 , respectively. By the numerical simulation method with the software of UDEC, the fractured zone height and the ratio were 42.5 and 10.12. By comparison of measured height data and UDEC numerical simulation, there were some differences between the measured height and the calculated results of UDEC numerical simulation method. The method of simulation can be used as the technical basis for the design of waterproof coal pillar in the future.
\end{abstract}

\section{Keywords}

Water Flowing Fractured Zone, Height Detection, Fracture Mining Ratio, Numerical Simulation

\section{Introduction}

The height detection of water flowing fractured zone is the basis of mine water prevention research. In the process of mining, if the aquifer exists and the water channel is formed in the mining surrounding rock, the mine water disaster may be formed. It is of great significance for water prevention in coal mine to accurately detect the development height of water flowing fractured zone.

At present, the methods to determine the water flowing fractured zone include field detection method, theoretical analysis method, empirical formula method, physical simulation and numerical simulation method [1]-[6]. Wang Hua conducts real-time detection of water flowing fractured zone using the field resistivity method, to obtain the maximum development height of water flowing fractured zone [7]. Liu Weitao takes simulation study on the development height 
of water flowing fractured zone formed by coal mining using RFPA and FLAC numerical simulation software [8]. Sun Xueyang et al. use the method of physical simulation experiment of similar materials to obtain the development height of water flowing fractured zone in a mine in Northeast China [9]. Xiao Lele et al. compare the two methods which are FLAC/3PD numerical simulation and physical simulation of similar materials to obtain the maximum height of water flowing fractured zone in Shandong mining area [10].

In this paper taking working face named 91105 as the research object, using the actually measured method and numerical simulation method, water flowing fractured zone was determined, and these two methods are compared by analyzing the results.

\section{Mining Condition}

The working face named 91105 is located in the northwest of the mine field, directly above it is the coal goaf of working faces named 41106, 41115 and 42106 respectively; in the north is the coal boundary protection pillar, and its outside boundary is the goaf area of other coal mines. The fault, its protective coal pillar and working face named 91103 are on the west side. The upper part of the east side is goaf for working face named 42105 , and in the south are the west wing belt, track, air return lanes and the protection coal pillar of auxiliary shaft industrial square.

Design mining coal seam of 91105 working face is $9-1$ coal, through geological data analysis, the strike angle of the coal seam is $11^{\circ}$ to $350^{\circ}$ to $251^{\circ}$, and the average dip Angle is $3^{\circ}$. The structure of the coal seam is simple, with a full thickness of $4.1 \mathrm{~m}$ to $5.1 \mathrm{~m}$ and an average thickness of $4.35 \mathrm{~m}$. The roof of the coal seam is siltstone with an average thickness of $4.59 \mathrm{~m}$, the bottom of the coal seam is carbonaceous mudstone, its average thickness is $1.49 \mathrm{~m}$.

The 9-1 coal seam is located below the 4-2 coal seam, the upper distance between the 4-2 coal seam is $18.1 \mathrm{~m}$ on average. For $4-2$ coal seam, it has been fully mined and its roof has all collapsed and settled during mining. The main aquifers which have great influence on the mining of 91105 working face include Shanxi Formation sandstone fissure aquifer, Taiyuan Formation sandstone fissure aquifer, karst fissure aquifer of Ordovician limestone, goaf water, drilling water and surface water. Wanghuolang River exists on the surface above the working face 91105, it is a seasonal river, the main source of water is meteoric water. In rainy season, Wanghuolang River may affect the mining to some extent.

The water inflow during mining is predicted by analogy method. The normal water inflow is expected to be $5 \mathrm{~m}^{3} / \mathrm{h}$, the maximum is to be $20 \mathrm{~m}^{3} / \mathrm{h}$, and the maximum discharge amount is $10 \mathrm{~m}^{3} / \mathrm{h}$.

\section{Height Detection Scheme of Water Flowing Fractured Zone}

In order to reduce the engineering cost and improve the observation accuracy, 
the subsection water injection observation method for underground uphole was adopted. The layout of pre-mining hole and post-mining hole was shown in Figure 1. The pre-mining holes named CQ1 and CQ2 were located in the belt channeling of the working face 91105 , hole CQ1 was about $41 \mathrm{~m}$ away from the stop-mining line of the working face, while hole CQ2 was $4 \mathrm{~m}$ away from the second obturator outside the belt channeling of the working face 91105. The hole named $\mathrm{CH} 1$ and $\mathrm{CH} 2$ were post-mining holes, they were located above the goaf of the working face 91,105. The drilling parameters are shown in Table 1.

The observation method of segmented water injection by borehole was adopted, and the upward observation method from the bottom up was taken. During the whole experiment the water injection pressure and flow rate were kept stable. The plugging expansion pressure of the pre-mining holes named CQ1 and CQ2 was about 0.5 MPa, and the plugging expansion pressure of the post-mining hole named $\mathrm{CH} 1$ is about 0.45 to $0.5 \mathrm{MPa}$, for $\mathrm{CH} 1$ was 0.35 to 0.4 $\mathrm{MPa}$. The borehole leakage data were obtained by segmented water injection observation. Through the analysis of the leakage data of $\mathrm{CH} 1$ borehole, it can be seen that the $73 \mathrm{~m}$ hole depth was the upper boundary of the determined water flowing fractured zone of 91105 working face, and the length of the plugging hole was $1 \mathrm{~m}$, then the height of the water flowing fractured zone of 91,105 working face determined by the observation of $\mathrm{CH} 1$ borehole was:

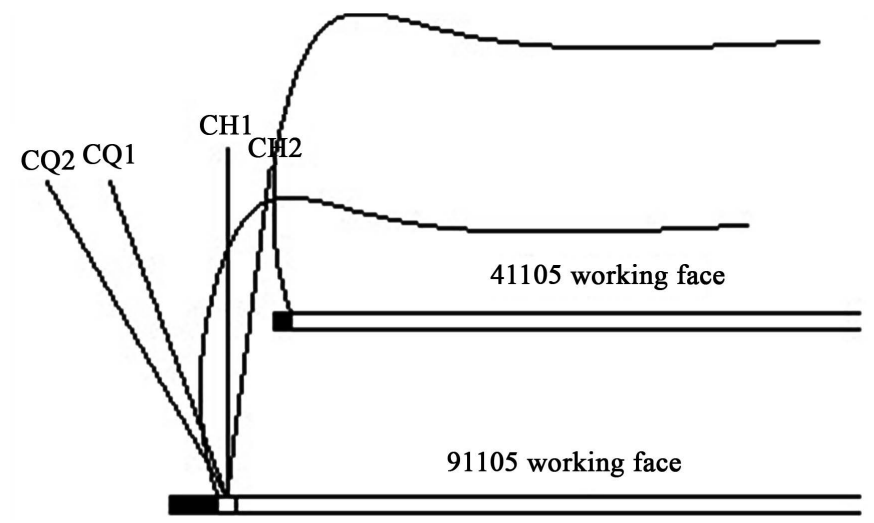

Figure 1. Schematic profile.

Table 1. List of drilling parameters.

\begin{tabular}{|c|c|c|c|c|c|c|}
\hline $\begin{array}{c}\text { Hole } \\
\text { number }\end{array}$ & Character & Diameter/mm & Direction $/^{\circ}$ & $\begin{array}{c}\text { Elevation } \\
\text { Angle/ }{ }^{\circ}\end{array}$ & $\begin{array}{c}\text { Hole } \\
\text { depth/m }\end{array}$ & $\begin{array}{l}\text { Observation } \\
\text { time }\end{array}$ \\
\hline CQ1 & $\begin{array}{l}\text { Hole before } \\
\text { mining }\end{array}$ & $\Phi 94$ & 335 & 55 & 78 & $\begin{array}{l}\text { June } 29^{\text {th }} \\
\text { morning shift }\end{array}$ \\
\hline CQ2 & $\begin{array}{l}\text { Hole before } \\
\text { mining }\end{array}$ & $\Phi 94$ & 340 & 50 & 85 & $\begin{array}{c}\text { June } 30^{\text {th }} \\
\text { morning shift }\end{array}$ \\
\hline $\mathrm{CH} 1$ & $\begin{array}{l}\text { Hole after } \\
\text { mining }\end{array}$ & $\Phi 94$ & 348 & 45 & 89 & $\begin{array}{l}\text { August } 24^{\text {th }} \\
\text { mid shift }\end{array}$ \\
\hline $\mathrm{CH} 2$ & $\begin{array}{l}\text { Hole after } \\
\text { mining }\end{array}$ & Ф94 & 350 & 50 & 82 & $\begin{array}{l}\text { August } 23^{\text {rd }} \\
\text { mid shift }\end{array}$ \\
\hline
\end{tabular}




$$
H_{l i 1}=(73+1) \sin 45^{\circ}=52.33 \mathrm{~m}
$$

for $\mathrm{CH} 2$ borehole, the $67 \mathrm{~m}$ hole depth was the upper boundary of the determined water flowing fractured zone, and the length of the plugging hole was $1 \mathrm{~m}$ too. Then, determined by the observation of $\mathrm{CH} 2$ borehole, the height of the water flowing fractured zone of 91105 working face was:

$$
H_{l i 2}=(67+1) \sin 50^{\circ}=52.09 \mathrm{~m}
$$

After analysis, the height of water flowing fractured zone observed in the underground uphole of 91105 working face was:

$$
H_{l i}=\max \left[H_{l i 1}, H_{l i 2}\right]=52.33 \mathrm{~m}
$$

according to 91105 Working Face Operation Regulations, the mining height was reduced to $4.2 \mathrm{~m}$ when $25 \mathrm{~m}$ away from the stop-mining line of the working face during the final mining period, so the fracture mining ratio was 12.46 .

\section{Numerical Simulation of the Height of Water Flowing Fractured Zone}

The development of water flowing fractured zone of 91105 working face was simulated by the software of UDEC. Taking into account of analysis purpose and the actual situation of working face, the length and height of the two-dimensional calculation model were set as $350 \mathrm{~m} \times 90 \mathrm{~m}$ respectively in order to eliminate the effects of the stress boundary and the displacement boundary. The strata with similar properties were divided into the same group along the strike of the mining face, and the simulated geometric model of the working face was shown in Figure 2.

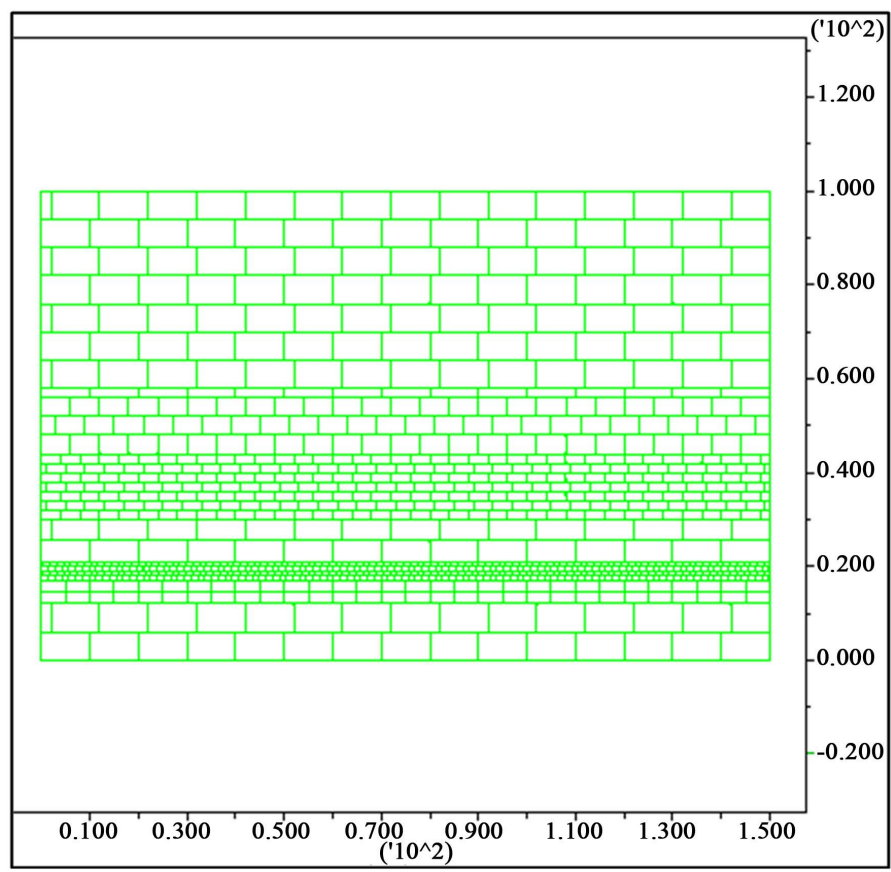

Figure 2. Schematic diagram of simulated geometric model of working face. 
1) Selection of boundary conditions

The bottom boundary, left boundary and right boundary of the model adopted zero displacement boundary condition, that is, the bottom boundary condition was fully constrained boundary $(\mathrm{u}=0$ and $\mathrm{v}=0)$ and the left and right boundary conditions were single constraint boundaries $(u=0, v \neq 0)$. The upper boundary was free and unconstrained, the strata above the upper boundary were applied as external loads on the upper boundary of the model.

2) Block division

Considering the occurrence conditions of coal seam and overlying strata, mining conditions of coal seam, rock mechanical strength characteristics of each layer and joint distribution, block division of each rock layer in the model was carried out. The bedrock blocks were basically divided according to the actual occurrence characteristics. The block size in the range of coal seam, direct roof and caving zone was small, while the block size of floor and old roof was relatively large. There were horizontal and vertical joints in each layer, and the strata were all staggered sedimentary blocks.

3) Determination of mechanical parameters

Rock was a kind of brittle material. When the load reached the yield strength, it would be destroyed and weakened, so it should be an elastoplastic body and Mohr-Coulomb criterion applies to this case. The tensile strength of rock was far less than the compressive strength, this constitutive model reflected the strength characteristics of rock comprehensively, and it was applicable to the shear failure of both plastic rock and brittle rock. The main rock mechanics parameters adopted in the calculation model mainly referred to the rock mechanics experiment of the roof and floor of No. 9 coal seam in the coal mine, which was shown in Table 2.

\section{Results and Discussion}

The model deformation obtained through simulation was shown in Figure 3, and the distribution of plastic area was shown in Figure 4, the development of fracture in rock formation in Figure 5 and the cloud diagram of vertical displacement of overburden in Figure 6.

According to calculated results, the distribution of plastic area and rock fracture development figure showed unit area where the failure occurred. Although in the process of mining, the previously generated fractured rock mass is mostly

Table 2. Mechanical parameters of rock and soil layer in model.

\begin{tabular}{ccccccccc}
\hline Position Lithology & $\begin{array}{c}\text { Density } \\
\mathrm{kg} / \mathrm{m}^{3}\end{array}$ & $\begin{array}{c}\text { Compressive } \\
\text { strength/Mpa }\end{array}$ & $\begin{array}{c}\text { Tensile } \\
\text { strength/Mpa }\end{array}$ & $\begin{array}{c}\text { Poisson's } \\
\text { ratio }\end{array}$ & $\begin{array}{c}\text { Cohesive } \\
\text { force }\end{array}$ & $\begin{array}{c}\text { Secant } \\
\text { modulus }\end{array}$ & $\begin{array}{c}\text { Tangent } \\
\text { modulus }\end{array}$ \\
\hline roof & siltstone & 2620 & 37.15 & 2.06 & 0.15 & 4.3 & 0.77 & 0.84 \\
roof & sandstone & 2480 & 60.2 & 4.56 & 0.32 & 4.6 & 1.06 & 1.13 \\
floor & mudstone & 2100 & 8.7 & 0.6 & & 0.9 & & \\
\hline
\end{tabular}




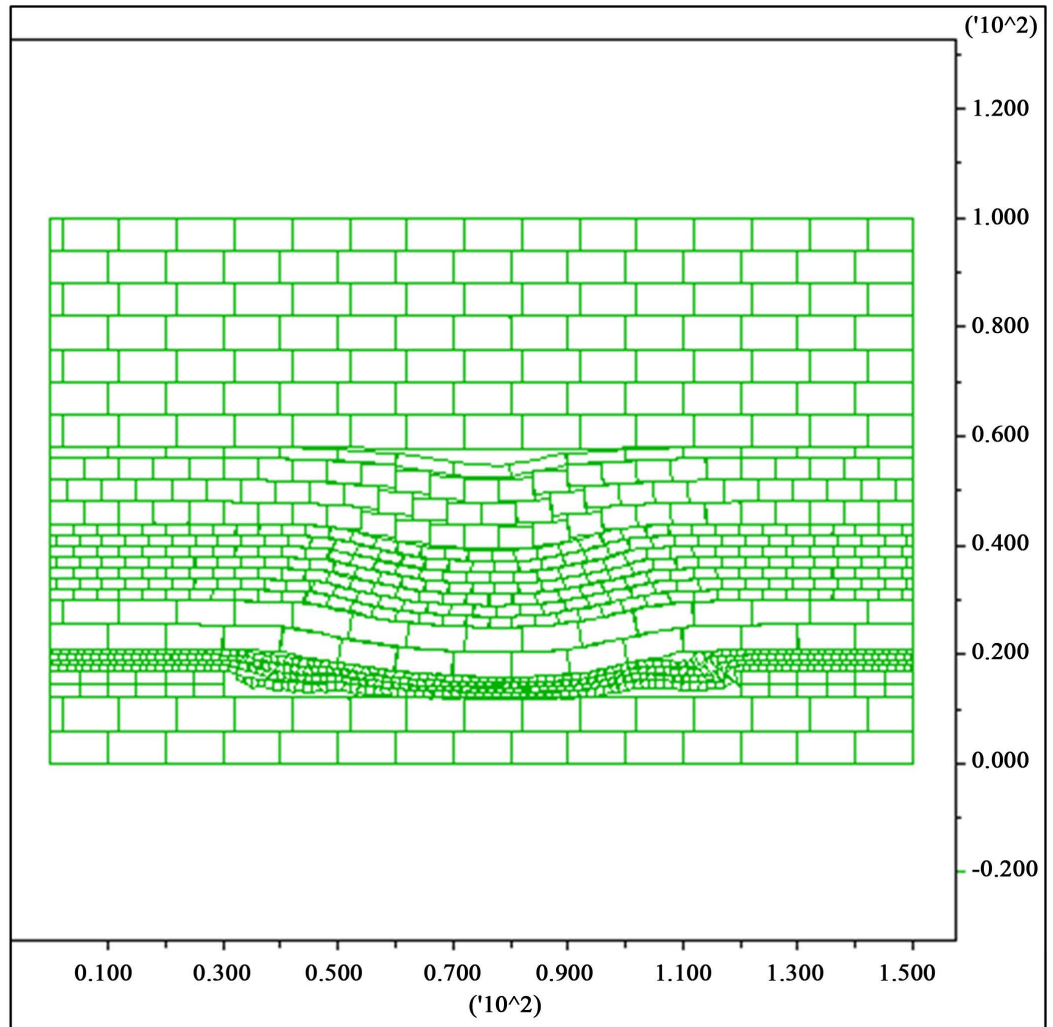

Figure 3. Deformation diagram of model.

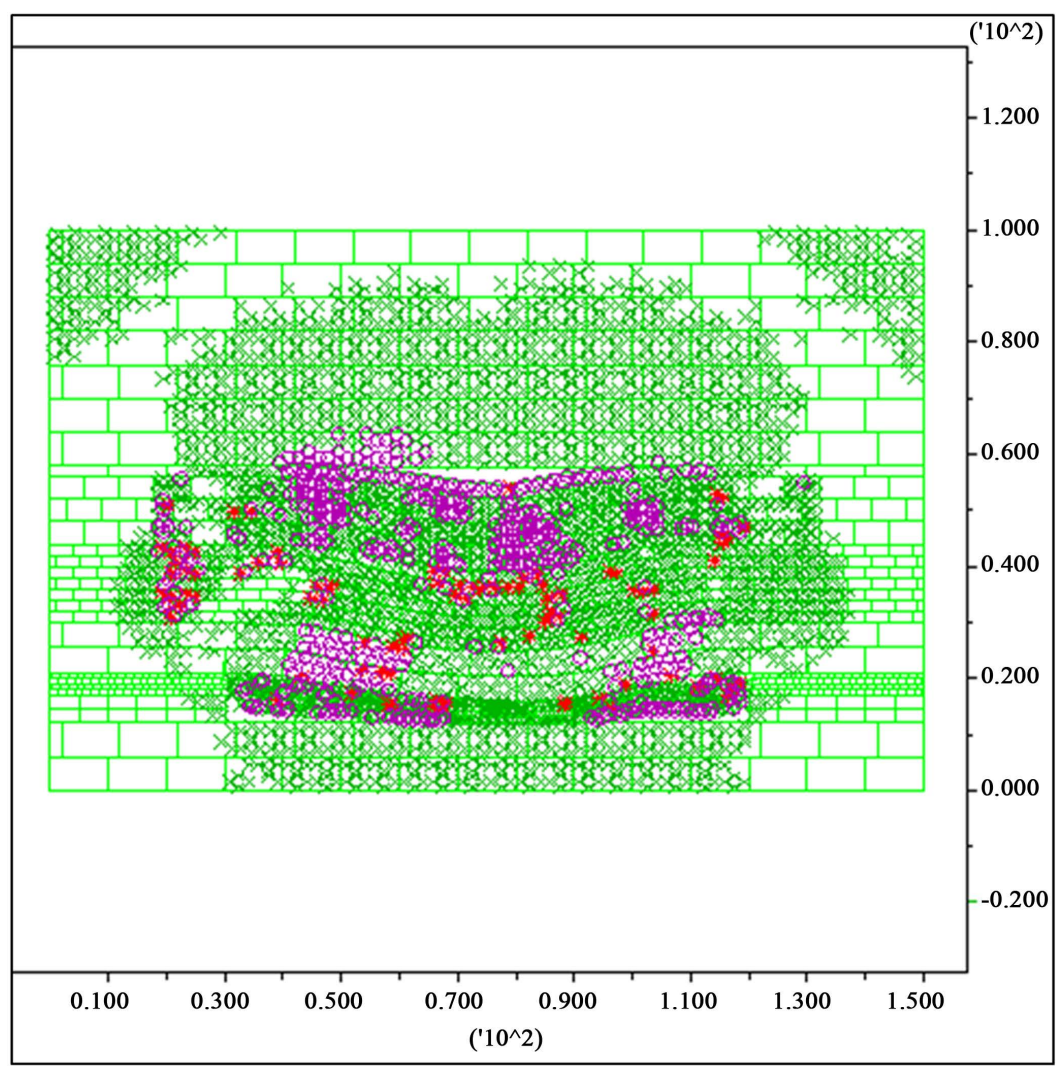

Figure 4. Plastic zone distribution. 


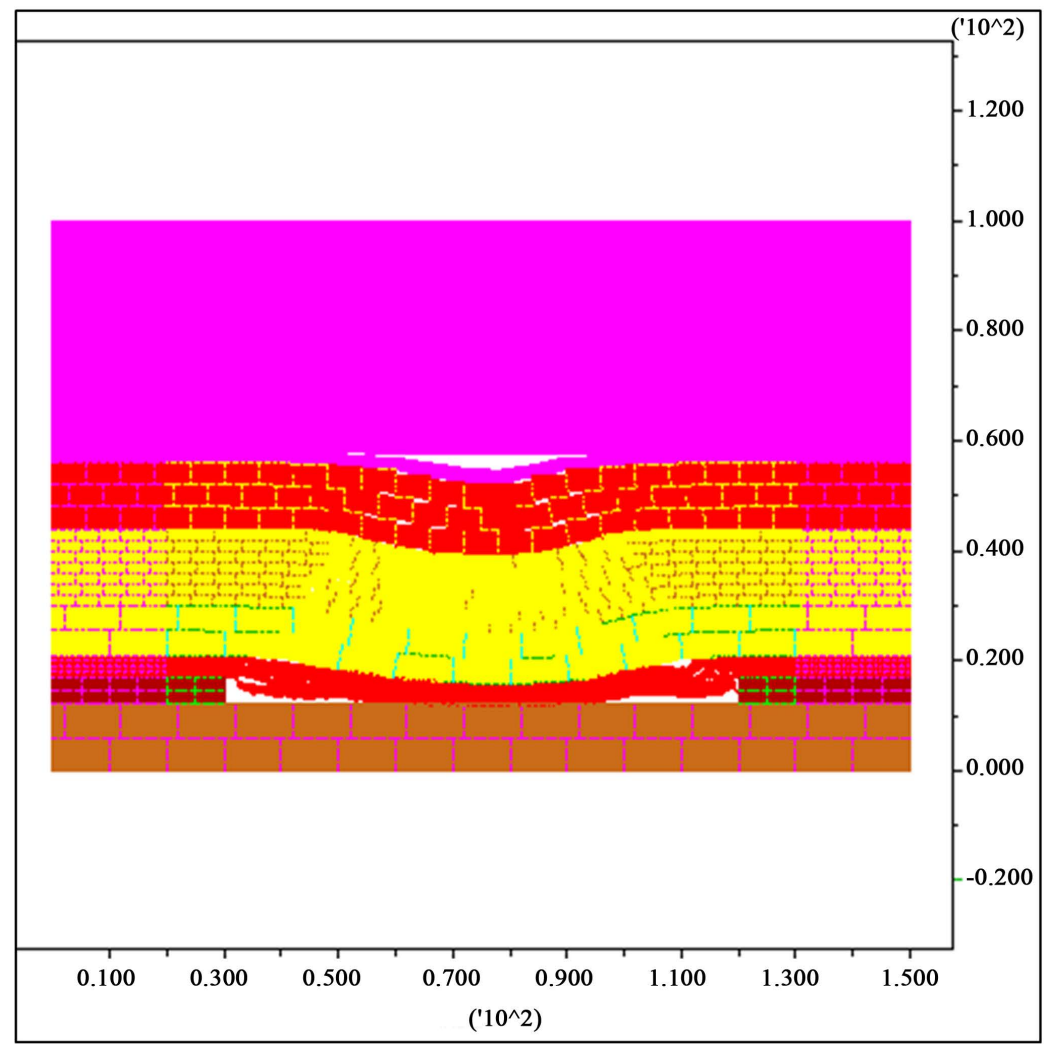

Figure 5. Fracture development diagram of rock formation.

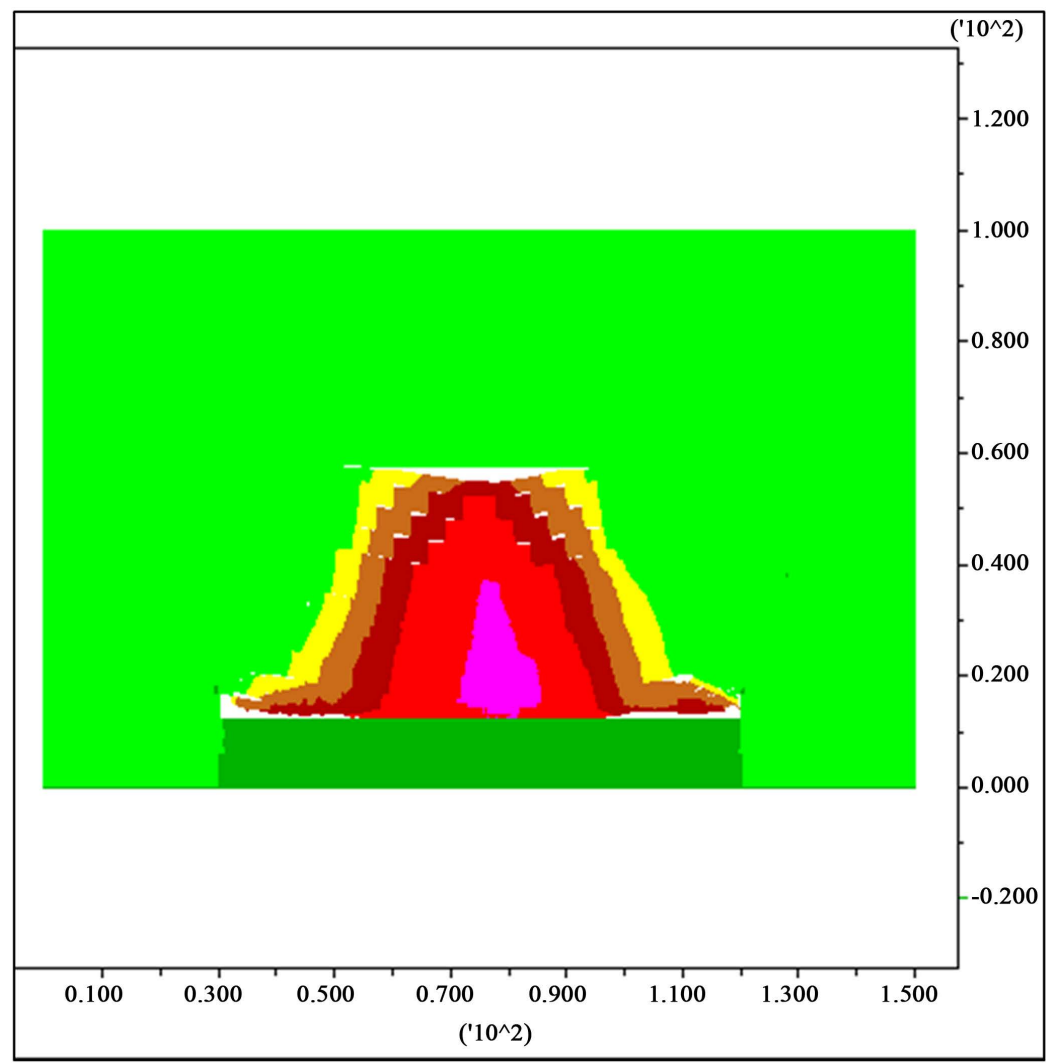

Figure 6. Cloud image of vertical displacement. 
in elastic state due to the stress redistribution or compaction, it is still regarded as the water flowing fractured zone because the fracture cannot be completely closed for the large stiffness of the rock, and thus the height of the water-conducting fractured zone can be obtained.

According to the cloud map of the vertical displacement in Figure 6, the height of the abrupt change in the vertical displacement (i.e., where the displacement isolines in the $\mathrm{Y}$ direction are dense) is taken as the height of the caving zone, But the height of the area where the rock strength exceeds the tensile strength is regarded as the height of the water flowing fractured zone.

It can be seen from Figure 5 that the contour lines are dense in some areas above the goaf, which shows that the displacement change quickly. There is a mutation in Figure 6, the upper portion of it is fissure zone, and the part underneath it as caving zone. The height of the caving zone can be determined as the maximum height of the contour line density above the goaf basing on the analysis.

It can be seen from the simulation results that the caving zone height of the 91,105 working face is $15.6 \mathrm{~m}$, and the water flowing fractured zone height is $42.5 \mathrm{~m}$. taking The coal seam mining thickness of $4.2 \mathrm{~m}$ as the standard, the conclusion is that the caving ratio of the 91105 working face is 3.71 , and the fracturing mining ratio is 10.12 .

\section{Conclusions}

1) According to the geological structure of 91105 working face, using simulation calculation, it is obtained that when 91105 working face mining 9-1 coal, the height of caving zone is $15.6 \mathrm{~m}$, the height of water flowing fractured zone is $42.5 \mathrm{~m}$, the caving and mining ratio is 3.71 , and the fissure and mining ratio is 10.12 .

2) The actual measured height of water flowing fractured zone is $52.33 \mathrm{~m}$; there are some differences between the measured height and the calculated results of UDEC numerical simulation method. The method of simulation can be used as the technical basis for the design of waterproof coal pillar in the future.

3) By comparison of measured height data and UDEC numerical simulation, the results of numerical simulation are small, with a relative error of $18.78 \%$. The field measuring method is reliable in predicting the development height of the water-conducting fractured zone of the working face.

\section{Acknowledgements}

This research is supported by the Science and Technology Fund Project of Shandong University of Science and Technology.

\section{Conflicts of Interest}

The author declares no conflicts of interest regarding the publication of this paper. 


\section{References}

[1] Wu, C., Wu, W., Yang, W., et al. (2010) Surveying on Two-Zone Height of Sublevel Strip Mining. Journal of Coal Science and Engineering (China), 16, 129-134. https://doi.org/10.1007/s12404-010-0204-8

[2] Spivak, A. and Khazins, V. (2013) Variation in Fractured Zone Rigidity by Dynamic Effects. Doklady Earth Sciences, 449, 328-331. https://doi.org/10.1134/S1028334X13030082

[3] Guo, W., Zou, Y. and Hou, Q. (2012) Fractured Zone Height of Long Wall Mining and Its Effects on the Overburden Aquifers. International Journal of Mining Science and Technology, 22, 603-606. https://doi.org/10.1016/j.ijmst.2012.08.001

[4] Xu, J., Wang, X., Liu, W., et al. (2009) Effects of Primary Key Stratum Location on Height of Water Flowing Fractured Zone. Chinese Journal of Rock Mechanics \& Engineering, 28, 380-385.

[5] Qian, M. and Xu, J. (1998) Study on the "O Shape" Circle Distribution Characteristics of Mining Induced Fractures in the Overlaying Strata. Journal of China Coal Society, 23, 466-469.

[6] Suo, Y. (2003) Characteristics of Ground Behavior of Fully Mechanized Caving Faces in Hard Thick Seams. Journal of Coal Science \& Engineering, 12, 25-29.

[7] Wang, H., Cheng, H. and Liu, S. (2007) Research on Timely Detection Technology of Water Conducting Fractured Zone Based on parallel Resistivity Method. Safety in Coal Mines, No. 7, 1-6.

[8] Liu, W., Liu, S., Huo, Z. and Li, L. (2014) Study on Simulation and Testing Technology for the Development of Roof Water-Conducting Crack Zone. Geotechnical Investigation \& Surveying, No. 11, 1-5.

[9] Sun, X., Li, P., Kou, Q., Fu, H., Li, C. and Miao, L. (2018) Simulation Experiment on Development Height of Water-Conducting Fractured Zone in Extra-Thick Coal Seam. Coal Technology, 37, 1-2.

[10] Xiao, L., Wang, Z., Wei, J., Niu Chao, Li, S. and Zhang, H. (2018) Study on the Development Law of Mining-Induced Fractures in Overlying Strata of Shallow Coal Seam with Thin Bedrock. Coal Technology, 37, 1-4. 